\title{
Forecasting the maximum compensation offer in the automobile BI claims negotiation process
}

\author{
By Mercedes Ayuso and Miguel Santolino \\ RISC-IREA Research Group. \\ Department of Econometrics, University of Barcelona. \\ Avda. Diagonal, 690. 08034 Barcelona. \\ Phone: 9340214 09/93 4021822 and 9340243 18. Fax: 93402 \\ 1821.
}

\begin{abstract}
Most motor bodily injury (BI) claims are settled by negotiation, with fewer than $5 \%$ of cases going to court. A well-defined negotiation strategy is thus very useful for insurance companies. In this paper we assume that the monetary compensation awarded in court is the upper amount to be offered by the insurer in the negotiation process. Using a real database, a log-linear model is implemented to estimate the maximal offer. Non-spherical disturbances are detected. Correlation occurs when various claims are settled in the same judicial verdict. Groupwise heteroscedasticity is due to the influence of the forensic valuation on the final compensation amount. An alternative approximation based on generalized inference theory is applied to estimate confidence intervals on variance components, since classical interval estimates may be unreliable for datasets with unbalanced structures.
\end{abstract}

JEL classification: C33, C53, G22

Subject and insurance Branch Code: IM11, IB40, IB41

Keywords: bodily injury claims compensation, negotiation process, generalized confidence intervals 


\section{Introduction}

Although motor bodily injury (BI) insurance claims are less frequent than those with only material damages, they represent the largest cumulative costs for motor insurers. Moreover, BI claims show a high variability in payments. Therefore, in most countries motor BI claims are not included in direct reimbursement systems (i.e. no-fault systems), and consequently, road traffic victims with personal damages must be compensated by the insurer of the driver responsible for the accident.

In general terms, if there are no discrepancies about who is at fault for the accident, insurers will attempt to reach a friendly agreement with the claimant as regards financial compensation. The compensation offered by the insurer in the negotiation process depends on the claim information available, and especially on the medical reports. The insurance company's medical staff evaluate the personal damage to the victim in successive examinations during his/her recovery, and when the insurance company has to negotiate the compensation, its monetary offer is mainly based on the information gathered during these examinations. In contrast, the sum requested by the claimant is founded on his/her own evidence (e.g. loss of earnings, independent medical reports and so forth).

When the two parties fail to reach an agreement on the claim compensation amount, the lawsuit will go to court and the compensation will be established by judicial verdict. In countries like the UK or the USA only $1 \%$ of claims are settled by judicial verdict (Lewis, 2006; Derrig and Rempala, 2006). In Spain, from where the database used in this paper was obtained, the percentage of motor BI claims settled in court rises to $5-10 \%$ of cases, depending on the insurance company. Most compensation payments are therefore the result of a negotiation process between parties. 
This paper analyzes the claim compensations awarded by courts in order to gain some insight into the compensation amount for which the BI claim could be settled prior to judicial decision. The aim was to estimate the maximum compensation amount that should be accepted by the insurer in the negotiation process (max offer). In particular, we consider that the expected BI claim compensation awarded by courts should be interpreted by the insurer as the maximum offer in the negotiation process. When the minimum compensation amount that the claimant is willing to accept is larger than this maximum offer, then the insurance company should decide to take it to court.

In the actuarial literature there is relatively little empirical research regarding the negotiation process between the insurer and the claimant. Indeed, previous studies have normally only dealt implicitly with the negotiation issue, and have mainly focused on quantifying the effect of suspicion of fraud on the BI claim settlement, this effect being considered as the negotiation margin on the final compensation. Crocker and Tennyson (2002), for instance, show that insurers pay on average lower compensations on claims with a low falsification cost. Loughran (2005) demonstrates that insurers under-indemnify general damages when special damages exceed their expected value and vice versa. Other authors have dealt with the optimal level of claim investigation according to the potential for reducing the claim cost (D'Arcy, 2005; Viaene et al., 2007).

Nevertheless, some recent contributions have analyzed variables that are directly related to the negotiation of the claim compensation (Derrig and Weisberg, 2004; Derrig and Rempala, 2006). In Derrig and Weisberg (2004), BI claim settlements are explained by variables such as the claimant compensation demand or whether a suit was filed. The authors suggest that more aggressive demands for pain and suffering damages frequently obtain higher claim compensations. Derrig and Rempala (2006) consider the negotiation 
process as a sequence of claimant demands and insurer offers until an agreement is reached. The authors fit a non-homogenous Poisson process to explain this stochastic process and show that two subsets of negotiations can be identified, fast and slow, which depend on the initial compensation demand or the period until the claim was reported, among other factors.

In our study, we apply a log-linear model to estimate BI claims compensations awarded by courts. Groupwise heteroscedasticity and correlation in the error term are possible, the former being due to the forensic performance. Correlation among observations occurs when more than one claim is involved in the same judicial sentence. Results are obtained from an unbalanced dataset which consists of few observations per unit record (maximum three claimants per verdict). Due to the sample framework, Satterthwaite's approximation (as implemented in SAS) does not perform correctly in order to construct confidence limits for the correlation parameter estimate. An alternative methodology based on generalized inference is thus applied for interval estimation (Tsui and Weerahandi, 1989). In particular, the Park-Burdick generalized confidence interval in the presence of groupwise heteroscedasticity is estimated (Park and Burdick, 2003; 2004).

The rest of the paper is structured as follows. A brief overview of the BI claim handling process is presented in the next section. Section 3 describes the data used in the empirical analysis. Section 4 defines the log-linear model specification and gives the estimation results, including the generalized confidence interval in the correlation parameter estimate. An example is presented to illustrate the application of the model in estimating the maximum compensation amount in a deal between parties. Finally, in Section 5, we summarize the main findings and present some concluding remarks. 


\section{Automobile liability insurance claim handling process}

Automobile liability insurance covers any damage as a result of an automobile accident for which the insured driver was responsible. Two types of damages due to the accident should be distinguished: material consequences and damages to the person. The former include material damages (car, personal possessions, etc.) and also any incurred medical expenses or loss of earnings (both, past and future). Damage to the person includes bodily injury and pain and suffering, which is defined as the physical or emotional distress resulting from the injury. Material damages and medical expenses seem to be easily justified by the claimant and verified by the insurer, and consequently, few disputes related to the compensation amount for these concepts are expected. Denial of responsibility for the accident is, in principle, the only reason for litigation. In contrast, the assessment of loss of earnings and damages to the person is more controversial and often causes disputes between claimants and insurers. This paper focuses on these damages, which are referred to as bodily injury (BI) claims.

BI claim handling refers to the process that starts when the accident occurrence is reported to the insurer and ends with the payment by the insurer for BI damages covered. The claim handling process (see Fig. 1) includes: i) the claim reporting, ii) the recovery period for the victim's injury, and finally, iii) the settlement phase. 


\section{Figure 1. Insurance claim settlement process}

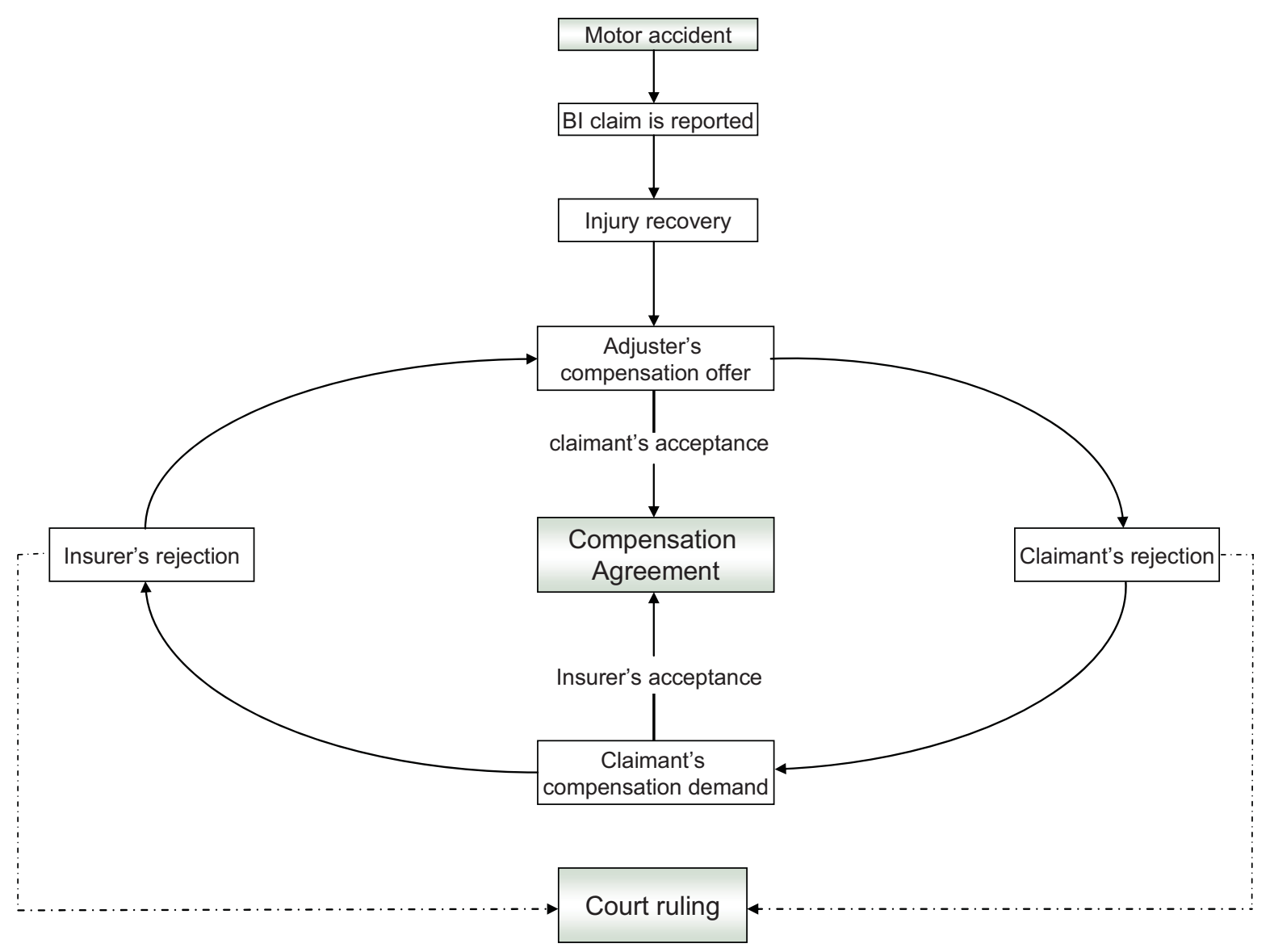

\subsection{Claim reporting}

When an accident takes place, victims who are not responsible for it may claim compensation for damages. Several countries require that a judicial process be initiated in such circumstances. Indeed, victims must file a lawsuit in order to be entitled to the compensation payment. Some countries, such as Ireland, have set up a previous statutory body that is responsible for assessing compensations with the aim of reducing litigation. Only if parties reject the assessment is the action pursued through the courts system. In these cases it is also the victim who must make the application to the statutory body. Under Spanish law, victims have six months from the time of the accident in which to file the 
lawsuit. Victims are entitled to claim only compensation for damages suffered, done by filing a tort suit, or also the punishment of the driver, for which a criminal suit is required.

At this stage the insurer obtains general claim information related to the accident characteristics, such as the number and type of vehicles involved, whether there were BI victims and so forth. Unlike road accidents with material damages, accidents with victims are usually communicated to the insurer shortly after they occur. Nevertheless, BI claims may remain unsettled for several years before victims are indemnified. This is because, firstly, the victim must be fully recovered and, subsequently, the compensation amount must be either agreed upon between the parties, assessed by a statutory body or, in the last resort, set by judicial order.

\subsection{Recovery period}

During the period in which the victim is recovering, the insurer wishes to know the evolution of his/her BI damages. With this objective, medical experts (appointed by the insurer) evaluate the injury severity of the victim in successive examinations. In Spain, motor bodily injury compensations must be dealt with in accordance with a legislative disability scale. The disability scale consists of an injury scoring system and a compensation scale. The scoring system provides a range of possible sequelae ${ }^{1}$ resulting from the accident and sets a maximum-minimum score for each one according to the injury severity. The monetary amount is determined on the compensation scale, which depends on the total score of sequelae (positively) and the age of the victim (inversely). Other countries, such as France or Italy, have similar systems of compensation. Normally, the

\footnotetext{
${ }^{1}$ Sequela is the definitive reduction of a person's physical and/or mental potential that can be medically explained.
} 
insurer's medical experts make their evaluations fit with sequelae and severity scores defined in the legislative scoring system.

The follow-up examinations carried out by the insurer are useful for reserving purposes during the time that the claim remains open. In Ayuso and Santolino (2007), for instance, this information is used to predict the final severity of the victim's injury at different stages during the life of the claim and, subsequently, the authors show that the individual claim provision can be estimated according to the predicted severity. When the victim has recovered, the follow-up examinations provide the core information for determining the compensation amount to offer in the negotiation. When the lawsuit follows the criminal procedure, a forensic doctor also examines the recovered victim. Forensic doctors must describe the victim's sequelae in accordance with the Spanish disability rating scale, but they are not obliged to measure severity by awarding a score; however, they may do so in order to assist the judge.

\subsection{The settlement phase: negotiation-litigation}

After the victim's recovery, the insurer and the claimant start negotiation in order to reach an agreement on the BI compensation amount. Normally, this negotiation is carried out by a lawyer and a staff adjuster, acting on behalf of the claimant and the insurance company, respectively. The first proposal of compensation is commonly made by the staff adjuster who communicates an offer to the claimant's lawyer. This compensation offer is based on the medical information available to the insurer; thus, the adjuster mainly assesses the claim by applying the compensation scale (provided in the legislative disability scale) to the severity score and number of recovery days considered by the medical expert in the last examination. 
In contrast, the lawyer requests claimant compensation for BI damages according to the medical examinations presented by his client and other personal evidence. If the insurer's offer satisfies the claimant's demand, then the adjuster and the lawyer will reach a compensation agreement. Indeed, the claim is then settled and the handling process ends. However, the lawyer will refuse the offer when it is not sufficient to cover the claim. At this point, the lawyer has two options: to present a counter-demand of compensation or to stop the negotiation and wait for a court hearing. In the latter, the BI claim compensation will be settled by judicial decision. When the lawyer chooses to request a second claim, then the settlement decision shifts to the adjuster. As with the lawyer previously, the adjuster may now accept the counter-demand, refuse it and present a counter-offer, or wait for a court hearing. These rounds of negotiation are repeated until a compensation deal is reached, or the date for the court hearing arrives.

The final result of the settlement process is uncertain and depends on multiple factors such as the negotiation strategies of both parties and whether or not the claimant is willing to wait until the court hearing for monetary compensation, and so on. Neither side in the negotiation has, in principle, a vested interest in the court option due to its associated higher costs and duration. Therefore, when the difference between the offer and demand amounts is not too large, the parties will be flexible in their respective positions in order to reach an agreement. However, determining how far the parties are willing to move from their initial positions before going to court is not an easy task. Indeed, despite the possibility of using game theory, i.e. the branch of science which deals with negotiation between agents and presents formal solutions (see Nelson Jr. 2002), factors other than strategies may play a role, for instance, the claimant's financial situation. 
In practice, the size of the increment from the initial offer to the final one depends on the negotiation experience of the adjuster and his skill in bargaining with the lawyer, as well, of course, on the lawyer's ability. Adjuster supervisors can monitor the performance of their adjuster teams and offer them general guidelines in the negotiation strategy. However, adjusters have broad autonomy during the negotiation process in decisions regarding increments of the offer. In the last resort, they also decide the maximum compensation to offer in the negotiation and, therefore, to go to court when this amount is exceeded. In this paper we develop an automated tool which helps the insurer's adjuster to estimate the maximum offer in the negotiation process. The model regressors relate to BI claim information collected by the insurer during the claim handling process.

\section{Spanish bodily injury claims database}

The dataset consists of 114 Spanish motor BI claims settled by judicial decision between 2001 and 2003. The database was provided by a Spanish insurer who was legally responsible for compensation payments. Each claim record represents a victim whom the insurer had to compensate for bodily injury damages. Some of these claims were judged in the same trial. In particular, there are 4 judicial verdicts involving three BI claims each, 14 involving two, and 74 verdicts involving only one claim. In total, the 114 BI claims were settled by 92 judicial verdicts or, in other words, around $20 \%$ of court verdicts relate to more than one victim.

Since insurer and plaintiff negotiate the compensation amount when the victim is fully recovered, we assume that the insurer followed up the victim during the recovery period and that at the time of negotiation the insurance company has the whole claim information available. In particular, it is assumed that the insurer's medical experts 
examined the victim at the beginning and end of the recovery period and wrote up an initial and final medical report, respectively. Explanatory variables included in the model are presented in Table 1. We also show some descriptive measures for the overall sample.

\section{TABLE 1. Variables in the model and some descriptive statistics}

\begin{tabular}{|c|c|c|c|}
\hline & & Mean & SD \\
\hline$y$ & Compensation amount awarded in judicial sentence in euros (on log scale). & 8.260 & 1.306 \\
\hline$x_{1}$ & 1 if the victim's vehicle is a car; $0=$ otherwise (e.g. van, motorbike, pedestrians). & 0.596 & 0.493 \\
\hline$x_{2}$ & 1 if male; $0=$ otherwise. & 0.509 & 0.502 \\
\hline$x_{3}$ & Victim's age ( 1 if age 0 to $9 ; 2$ if 10 to 19 ; and so forth). & 3.868 & 1.686 \\
\hline$x_{4}$ & 1 if the last medical report is the same as the initial medical report; $0=$ otherwise. & 0.316 & 0.467 \\
\hline$x_{5}$ & Number of sequelae (final medical report). & 1.114 & 1.655 \\
\hline$x_{6}$ & Sequelae number variation across reports (final medical report minus initial one). & 0.009 & 0.917 \\
\hline$x_{7}$ & Number of recovery days with disability for working (final medical report). & 53.132 & 63.027 \\
\hline$x_{8}$ & Number of recovery days without disability for working (final medical report). & 37.596 & 59.699 \\
\hline$x_{9}$ & $\begin{array}{l}\text { Variation in the number of recovery days unable to work across reports (final } \\
\text { medical report minus initial one). }\end{array}$ & 2.079 & 37.601 \\
\hline$x_{10}$ & $\begin{array}{l}\text { Variation in the number of recovery days not unable to work across reports (final } \\
\text { medical report minus initial one). }\end{array}$ & 7.210 & 32.456 \\
\hline$x_{11.1}$ & $\begin{array}{l}1 \text { if forensic doctor examines the victim and assesses the severity of his/her } \\
\text { sequelae; } 0=\text { otherwise. }\end{array}$ & 0.210 & 0.409 \\
\hline$x_{11.2}$ & $\begin{array}{l}1 \text { if forensic doctor examines the victim and indicates his/her sequelae but doesn't } \\
\text { assess the severity of them; } 0=\text { otherwise. }\end{array}$ & 0.342 & 0.477 \\
\hline$x_{11.3}$ & 1 if forensic doctor examines the victim and doesn't award sequelae; $0=$ otherwise. & 0.342 & 0.477 \\
\hline$x_{11.4}$ & 1 if there was no forensic report (civil procedure); $0=$ otherwise. & 0.105 & 0.308 \\
\hline
\end{tabular}

Regression variables refer to attributes of the victim such as gender $\left(x_{2}\right)$ and age $\left(x_{3}\right)$, type of victim's vehicle and information collected in medical reports. Regarding the vehicle type, a dichotomous variable $\left(x_{1}\right)$ is included which indicates whether the casualty was travelling by car. As for the information from the final medical report, we consider the number of sequelae $\left(x_{5}\right)$ and the number of recovery days caused by the accident according to the medical expert's examination. In Spain, legislation distinguishes between recovery days in which the victim was disabled for working purposes from those without disability for working. Both variables are included in the model regression $\left(x_{7}\right.$ and $\left.x_{8}\right)$. In order to 
avoid collinearity problems, the variations between reports rather than the raw information from the initial medical report were considered. In particular, we observe the variation across medical reports in the number of sequelae $\left(x_{6}\right)$ and the number of recovery days disabled and not disabled for working $\left(x_{9}\right.$ and $x_{10}$ ). In addition, a control variable is added to indicate those claims in which only one medical report was produced $\left(x_{4}\right)$.

Finally, four categorical variables related to the forensic performance have been defined, and these variables reflect the different ways in which the forensic doctor participates in the claim settlement process. The first one $\left(x_{11.1}\right)$ indicates whether the forensic doctor examined the victim, awarded him/her sequelae and assessed their severity. The second one $\left(x_{11.2}\right)$ refers to whether the forensic doctor examined the victim, awarded sequelae but didn't assess their severity. The third option $\left(x_{11.3}\right)$ is that the forensic doctor evaluated the victim but didn't assign him/her sequelae. The previous three categories refer to criminal suits. However, when the claimant files a tort suit the forensic doctor does not participate. This situation is considered in our fourth category $\left(x_{11.4}\right)$. It should be noted that we have included only these categorical regressors from the information collected in the forensic report to prevent civil lawsuits from being treated as missing values in the dataset.

\section{Insurer's maximum offer of compensation}

Our goal is to estimate the maximum claim compensation to be offered by the insurer in the negotiation process. As previously remarked, we consider that the monetary compensation which would be awarded by the judge in the judicial proceeding is the maximum offer of compensation that should be made by the insurer in the negotiation. A log-linear model with nonspherical disturbances is implemented to estimate BI claims compensations awarded by courts. 


\subsection{Model specification}

Insurance data frequently present an unbalanced design, i.e. there is not the same number of observations per unit record of the data set (e.g. the number of covered risks in each individual policy). Log-linear models may be implemented for both balanced and unbalanced data, although the inference techniques used depend on the type of data (Khuri et al., 1998). In the current application, a log-linear regression model has been applied to estimate the claim compensation awarded in courts. Let us suppose that the data set consists of $n$ subjects, where $n_{i}$ is the number of observations for the $i$ th subject, $1 £ i £ n$. In our specification $i$ indicates the judicial verdict $\left(1 £ i £\right.$ 92) and $n_{i}$ the number of claims settled in the $i$ th verdict $\left(1 £ n_{i} £ 3\right)$. Our database is unbalanced since not all judicial verdicts involve the same number of BI claims. The overall sample size $N$ is obtained as the sum of all the claims settled in each verdict, $\underset{i=1}{92} n_{i}=114$.

Groupwise heteroscedasticity is due to the forensic performance. Note that the forensic examination is the only impartial evaluation of the victim's severity, and thus it is likely to have a strong influence on the judge's decision. At this point, we suggest that claims may have different variability in compensations depending on whether the forensic doctor participates or not in the claim settlement process, and also on the nature of this participation. The residual variance is parameterized as $s_{e_{g}}^{2}$, where $g$ indicates the category of the variable related to the forensic performance $x_{11 . g}$ with $g=1, \ldots, 4$ (as shown in Table 1). The residual correlation among BI victims judged in the same court verdict is also considered. The correlation parameter is $s_{a}^{2}$. The model is specified as follows:

$$
y_{i j}: N\left(\boldsymbol{x}_{i j} \boldsymbol{\beta}, \sigma_{\varepsilon_{\mathrm{g}}}^{2}+\sigma_{\alpha}^{2}\right), \quad i=1, \mathrm{~K}, 92, \quad 1 \leq j \leq n_{i} \text {, }
$$


where $y_{i j}$ is the compensation amount (on log scale) awarded by the judge in the $i$-th judicial verdict to the $j$-th victim and with $g$-th residual variance, such that $1 \leq g \leq 4$. $\boldsymbol{\beta}$ $(p \times 1)$ is the vector of $p$ unknown parameters and, finally, $\boldsymbol{x}_{i j}(1 \times p)$ is the design vector. Independence between judicial verdicts is assumed.

Variance components are estimated by maximizing the restricted likelihood function (REML), $L_{R E M L}=\operatorname{det}\left(\sum_{i=1}^{n} \mathbf{X}_{i}^{\prime} \mathbf{V}_{i}^{-1} \mathbf{X}_{i}\right)^{-1 / 2} \cdot L_{M L}$, where $\mathbf{X}_{i}\left(n_{i} \times p\right)$ and $\mathbf{V}_{i}\left(n_{i} \times n_{i}\right)$ are the design and the covariance matrices of the $i$-th sentence, and $L_{M L}$ the likelihood function (Verbeke and Molenberghs, 2000). REML estimators are generally preferred to maximum likelihood estimators due to their optimal minimum variance properties (for a detailed discussion, see Robinson, 1987; Searle et al., 1992). When variance components are replaced by their estimators, the empirical $\hat{\boldsymbol{\beta}}$ is obtained as $\hat{\boldsymbol{\beta}}=\left(\sum_{i=1}^{n} \mathbf{X}_{i}^{\prime} \hat{\mathbf{V}}_{i}^{-1} \mathbf{X}_{i}\right)^{-1} \sum_{i=1}^{n} \mathbf{X}_{i}^{\prime} \hat{\mathbf{V}}_{i}^{-1} \boldsymbol{y}_{i}$. Statistical inference is based on Wald and likelihood ratio tests (Khury et al., 1998). Confidence intervals on variance parameters are estimated by means of Satterthwaite's approximation, which takes into account the fact that these parameters have a lower boundary at zero.

\subsection{Estimation results}

The results are presented in Table 2, which also shows the $90 \%$ confidence intervals for the parameter estimates. The Wald limits were estimated for the regression parameters and the Satterthwaite limits for the parameters of the residual variance. For unbalanced designs, Satterthwaite's approximation can produce unacceptably liberal confidence intervals on $\sigma_{\alpha}^{2}$ (Burdick and Graybill, 1992). For this reason, the Park-Burdick generalized confidence interval is provided in Table 2. Although alternative generalized confidence intervals on 
$\sigma_{\alpha}^{2}$ may usually be derived (Zhou and Mathew, 1994), Arendacká (2005) demonstrated that the generalized confidence interval provided by Park and Burdick performs best in terms of the confidence interval yielded.

TABLE 2. Estimation results $(90 \%$ confidence level)

\begin{tabular}{|c|c|c|c|c|c|}
\hline & & Coeff. & $p$-value & $\begin{array}{l}\text { Lower- } \\
\text { bound }\end{array}$ & $\begin{array}{l}\text { Upper- } \\
\text { bound }\end{array}$ \\
\hline$\beta_{0}$ & Constant & 8.393 & $0.000 * * *$ & 7.908 & 8.880 \\
\hline$x_{1}$ & $\begin{array}{l}1 \text { if the victim's vehicle is a car; } 0=\text { otherwise (e.g. } \\
\text { van, motorbike, pedestrians). }\end{array}$ & -0.215 & 0.119 & -0.443 & 0.013 \\
\hline$x_{2}$ & 1 if male; $0=$ otherwise. & -0.766 & $0.004 * * *$ & -1.152 & -0.380 \\
\hline$x_{3}$ & $\begin{array}{l}\text { Victim's age ( } 1 \text { if age } 0 \text { to } 9 ; 2 \text { if } 10 \text { to } 19 \text {; and so } \\
\text { forth). }\end{array}$ & 0.051 & 0.216 & -0.019 & 0.121 \\
\hline$x_{4}$ & $\begin{array}{l}1 \text { if the last medical report is the same as the initial } \\
\text { medical report; } 0=\text { otherwise. }\end{array}$ & -0.878 & $0.001 * * *$ & -1.222 & -0.534 \\
\hline$x_{5}$ & Number of sequelae (last medical report). & 0.216 & $0.002 * * *$ & 0.121 & 0.310 \\
\hline$x_{6}$ & $\begin{array}{l}\text { Sequelae number variation across reports (last } \\
\text { medical report minus initial one). }\end{array}$ & -0.270 & $0.013 * *$ & -0.435 & -0.105 \\
\hline$x_{7}$ & $\begin{array}{l}\text { Number of recovery days with disability for } \\
\text { working (last medical report). }\end{array}$ & 0.009 & $0.000 * * *$ & 0.006 & 0.011 \\
\hline$x_{8}$ & $\begin{array}{l}\text { Number of recovery days without disability for } \\
\text { working (last medical report). }\end{array}$ & 0.006 & $0.005 * * *$ & 0.003 & 0.008 \\
\hline$x_{9}$ & $\begin{array}{l}\text { Variation in the number of recovery days unable to } \\
\text { work across reports (last medical report minus } \\
\text { initial one). }\end{array}$ & -0.005 & $0.016^{* *}$ & -0.008 & -0.002 \\
\hline$x_{10}$ & $\begin{array}{l}\text { Variation in the number of recovery days not } \\
\text { unable to work across reports (last medical report } \\
\text { minus initial one). }\end{array}$ & -0.001 & 0.626 & -0.006 & 0.004 \\
\hline$x_{11.3}$ & $\begin{array}{l}1 \text { if forensic doctor examines the victim and doesn't } \\
\text { award sequelae; } 0=\text { otherwise. }\end{array}$ & -0.716 & $0.000 * * *$ & -0.974 & -0.457 \\
\hline$x_{12}$ & 1 if $x_{2}=0$ y $x_{4}=0 ; 0=$ otherwise. & -0.660 & $0.023 * *$ & -1.109 & -0.210 \\
\hline$\sigma_{\alpha}^{2}$ & Correlation parameter & 0.028 & 0.403 & 0.000 & 0.280 \\
\hline$\sigma_{\varepsilon_{1}}^{2}$ & Residual variance if $x_{11.1}=1$ & 0.768 & $0.001 * * *$ & 0.478 & 1.475 \\
\hline$\sigma_{\varepsilon_{2}}^{2}$ & Residual variance if $x_{11.2}=1$ & 0.172 & $0.096^{*}$ & 0.069 & 1.201 \\
\hline$\sigma_{\varepsilon_{3}}^{2}$ & Residual variance if $x_{11.3}=1$ & 0.466 & $0.001 * * *$ & 0.297 & 0.859 \\
\hline$\sigma_{\varepsilon_{4}}^{2}$ & Residual variance if $x_{11.4}=1$ & 0.664 & $0.021 * *$ & 0.346 & 1.897 \\
\hline
\end{tabular}


The chi-square statistic was computed as minus two times the difference between the $\log$ restricted-likelihood for the model and the log restricted-likelihood when $\sigma_{\alpha}^{2}=0$ and $\sigma_{\varepsilon_{g}}^{2}=\sigma_{\varepsilon}^{2}, \forall g$. The significance of the statistic indicates that a model with spherical perturbations is rejected.

Regarding the estimated parameters of the regressors, all coefficients are significant, except those related to the victim's vehicle $\left(x_{1}\right)$, the victim's age $\left(x_{3}\right)$ and the variation across reports in the number of recovery days not disabled for working $\left(x_{10}\right)$. Many authors have shown that the victim's age is positively correlated with the motor bodily injury severity (Lee and Abdel-Aty, 2005; Wang and Kockelman, 2005; Ayuso and Santolino, 2007). In contrast, and as pointed out in section 2.2, the monetary value stipulated in the Spanish legislative disability scale for the compensation assessment of the motor victim's injury is inversely related to the victim's age. Therefore, we suggest that the lack of explanatory capacity for this variable in the model could be due to the fact that the aforementioned effects counteract each other. Hence, older victims have more serious injuries resulting from the accident, but at the same time they receive less money for them.

The remaining parameter influences on the claim compensation are as expected, for example, the bodily injury severity awarded in the last medical report is positively related to the final claim compensation, and the expected compensation decreases when the forensic doctor examined the victim and didn't award sequelae. Note that two of the three variables from the initial medical report $\left(x_{6}, x_{9}\right)$ have significant coefficients and with a negative sign. As a prudent practice, medical experts often consider a higher injury severity in the initial examination than in the final one, and thus $x_{6}$ and $x_{9}$ usually take negative values. Finally, whenever the final medical report is different from the initial one 
or the victim is a woman, the expected claim compensation increases. However, when these features are observed at the same time, both marginal effects are partially counterbalanced by the influence of the joint variable $x_{12}$.

Unlike residual variance estimates, the correlation parameter estimate is near zero. This result is surprising since it would seem naive to believe that victims settled in the same judicial verdict are not correlated. Thus, we consider that the low value of the correlation parameter estimate is due to the sample design. Indeed, as was pointed out in section 3, only a few sample individuals (i.e. judicial sentences) have more than one observation (i.e. BI victims involved). Therefore, it makes sense to construct the upperlimit estimate of the parameter with a confidence level. Note that the upper-bound of the Park-Burdick generalized confidence interval is around 0.3.

\subsection{Empirical estimation of the maximal compensation offer in the negotiation process}

In this section an example of predicting the maximum insurer offer in the negotiation process is presented for two different scenarios. The upper-bound of the maximum offer, for a given confidence level, is also computed. Predictions are on a logarithmic scale and, therefore, they must be transformed to the original scale following the well-known characteristics of the lognormal distribution, i.e. if $\ln (\eta): N\left(\mu, \sigma^{2}\right)$ then $E[\eta]=e^{\mu+0,5 \sigma^{2}}$ and $\operatorname{Var}[\eta]=e^{2 \mu+\sigma^{2}}\left(e^{\sigma^{2}}-1\right)$.

Let us suppose that the insurance company wants to negotiate the BI compensation amount for the victims of two claims (A and B). Claim A concerns a 20-year-old man who suffered a motorbike accident. The initial and final medical reports are available to the insurer. In both medical reports the medical experts considered that the victim required 35 
days for recovery and that he was temporarily disabled for work during this period. Furthermore, the victim did not suffer sequelae after recovery. The lawsuit follows a civil procedure and, therefore, the forensic doctor does not participate.

Claim B concerns a 35-year-old woman who was injured in an accident with her car. Medical experts of the responsible driver's insurance company examined the victim at the beginning and end of the recovery period, and in both examinations the same injury severity was awarded. According to these examinations, the woman had four sequelae resulting from the accident and was temporarily disabled for work for 50 days. In addition, she needed a further 15 recovery days after she became able to work. Since the victim filed a criminal suit against the insured driver for her injuries, she was also examined by a forensic doctor. The insurer knows that the forensic doctor awarded sequelae to her but did not assess their severity. Predictions of maximal compensation offers and upper-bounds for both claims are shown in Table 4.

TABLE 4. Example of predicting the maximum compensation offer (in Euros)

\begin{tabular}{|c|c|c|c|c|c|}
\hline \multicolumn{3}{|c|}{ CLAIM A } & \multicolumn{3}{|c|}{ CLAIM B } \\
\hline $\begin{array}{l}\text { Predicted } \\
\text { max offer }\end{array}$ & $\begin{array}{l}\text { Std. Err. } \\
\text { Predic.* }\end{array}$ & $\begin{array}{c}\text { Upper } \\
\text { bound }^{ \pm}\end{array}$ & $\begin{array}{l}\text { Predicted } \\
\text { max offer }\end{array}$ & $\begin{array}{l}\text { Std. Err. } \\
\text { Predic.* }\end{array}$ & $\begin{array}{l}\text { Upper } \\
\text { bound }^{ \pm}\end{array}$ \\
\hline on log scale & & & on log scale & & \\
\hline 8.092 & 0.151 & 8.340 & 9.774 & 0.277 & 10.228 \\
\hline on original scale & & & on original sce & & \\
\hline 3305.69 & 502.018 & 4129.00 & 18258.11 & 5156.079 & 26714.08 \\
\hline
\end{tabular}

For claim A (Table 4, first three columns) the insurance company should go to court when the claimant does not accept compensation lower than $€ 3305.69$ in the 
negotiation process. Furthermore, the insurer knows that in the event of a court ruling the compensation awarded by judicial verdict would be lower than $€ 4129.00$, with a $95 \%$ confidence level. In contrast, for claim B (Table 4, last three columns) the maximum compensation offered in the negotiation process rises to $€ 18258.11$, with the insurer being aware that the claim compensation awarded by a court ruling could reach $€ 26714$.08, once again with a confidence level of $95 \%$.

Therefore, we have shown that the presented methodology provides a guideline for estimating the maximum compensation for BI damages to be offered in the negotiation process. Indeed, we provide the insurance adjuster with a tool to determine the margin in the claim negotiation before going to court. Furthermore, since distributional assumptions are considered, the deviation from the expected maximum compensation cost with a confidence level can also be known by the adjuster.

In this paper we have assumed that the correlation in residuals is caused by unobserved factors resulting from the same court verdict. Therefore, only those parameters which are common for all individuals were estimated. However, the presented methodology would still be valid when the cause of correlation was exclusively that compensations were settled by the same adjudicator. Since it is an observed factor it would also be necessary to estimate the subject-specific parameter, i.e. the deviation from the expected mean compensation associated with the aforementioned person. This would be achieved by including a random-effect in the model specification.

\section{Conclusions}

Motor insurers always negotiate with accident victims about financial compensation for injuries before taking the dispute to court. In this paper we develop a methodology that 
assists insurance staff in the negotiation of bodily injury (BI) claims. In particular, we show how to estimate the maximum compensation that the insurer should be willing to offer the claimant in the negotiation process. In addition, the statistical basis of the suggested methodology enables the upper-bound maximal offer to be computed with a confidence level. By fixing the negotiation limit, the insurer provides staff adjusters with homogeneous and unequivocal norms for the settlement of disputes. Nevertheless, the maximum offer of compensation provided by our methodology supplements — but does not replace — the subjective claim assessment made by the insurance adjuster. Indeed, the methodology allows the insurer to assess the staff adjusters' work, monitoring how much money is saved when claims are negotiated instead of settled by judicial verdict.

A log-linear model is implemented to estimate the maximum offer according to attributes of the victim and characteristics of the claim record, including medical reports. The model specification includes residual correlation among BI victims involved in the same judicial verdict. Due to the unbalanced structure of the data, classical interval estimates on the correlation parameter are not reliable. This problem is overcome through estimation of the Park-Burdick generalized confidence interval. Empirical evidence has found that financial settlements awarded by courts present different variability according to the forensic participation.

Finally, note that the suggested methodology could also have implications for the insurer's reserving process since BI claims settled prior to a court ruling take on average less time to close. Therefore, reaching a negotiated agreement means reducing the time that the claim is provisioned within the company. 


\section{Acknowledgements}

This work has received support from the Spanish Ministry of Education and Science and FEDER grant SEJ2005-00741/ECON. 


\section{References}

Arendacká, B., 2005. Generalized confidence intervals on the variance component in mixed linear models with two variance components. Statistics, 39(4), 275-286.

Ayuso, M., Santolino, M., 2007. Predicting automobile claims bodily injury severity with sequential ordered logit models. Insurance: Mathematics and Economics, 41(1), 71-83.

Burdick, R.K., Graybill, F.A., 1992. Confidence intervals on variance components. New York: Marcel Dekker.

Crocker, K.J., Tennyson, S., 2002. Insurance fraud and optimal claims settlement strategies. Journal of Law \& Economics, 45(2), 469-507.

D’Arcy, S., 2005. Predictive modeling in automobile insurance: a preliminary analysis. In: World Risk and Insurance Economics Congress, August, Salt Lake City.

Derrig, R.A., Rempala, G.A., 2006. A statistical analysis of the effect of anchoring in the negotiation process of automobile bodily injury liability insurance claims. In: $C A S$ predictive modelling seminar, October 4, Boston.

Derrig, R.A., Weisberg, H.I., 2004. Determinants of total compensation for auto bodily injury liability under no-fault: investigation, negotiation and the suspicion of fraud. Insurance and Risk Management, 71(4), 633-662.

Harville, D., Jeske, D., 1992. Mean squared error of estimation or prediction under a general linear model. Journal of the American Statistical Association, 87(419), 724-731.

Khuri, A.I., Mathew, T., Sinha, B., 1998. Statistical tests for mixed linear models. New York: Wiley series in probability and mathematical statistics. 
Lee, C., Abdel-Aty, M., 2005. Comprehensive analysis of vehicle-pedestrian crashes at intersections in Florida. Accident Analysis \& Prevention, 37(4), 75-786.

Lewis, R., 2006. How important are insurers in compensating claims for personal injury in the U.K.? The Geneva Papers on Risk and Insurance-Issues and Practice, 31(2), 323-339.

Loughran, D.S., 2005. Deterring fraud: the role of general damage awards in automobile insurance settlements. Journal of Risk and Insurance, 72(4), 551-575.

Nelson Jr., W.R., 2002. Equity or intention: it is the thought that counts. Journal of Economic Behaviour and Organization, 48, 423-430..

Park, D.J., Burdick, R.K., 2003. Performance of confidence intervals in regression models with unbalanced one-fold nested error structures. Communications in Statistics-Simulation and Computation, 32(3), 717-732.

Park, D.J., Burdick, R.K., 2004. Confidence intervals on total variance in a regression model with an unbalanced onefold nested error structure. Communications in StatisticsTheory and Methods, 33(11), 2735-2743.

Robinson, D.L., 1987. Estimation and use of variance components. The Statistician, 36, 314.

Searle, S., Casella, G., McCulloch, C., 1992. Variance components. New York: Wiley series in probability and mathematical statistics.

Tsui, K., Weerahandi, S., 1989. Generalized $p$-values in significance testing of hypothesis in the presence of nuisance parameters. Journal of the American Statistical Association, 84(406), 602-607. 
Verbeke, G., Molenberghs, G., 2000. Linear mixed models for longitudinal data. New York: Springer.

Viaene, S., Ayuso, M., Guillén, M., Van Gheel, D., Dedene, G., 2007. Strategies for detecting fraudulent claims in the automobile insurance industry. European Journal of Operational Research, 176, 565-583.

Wang, X., Kockelman, K., 2005. Use of heteroscedastic ordered logit model to study severity of occupant injury: distinguishing the effects of vehicle weight and type. Transportation Research Record, 1908, 195-204.

Zhou, L., Mathew, T., 1994. Some tests for variance components using generalized $p$ values. Technometrics, 36(4), 394-402. 